\title{
Diagnóstico ambiental de indústrias de fabricação de estruturas metálicas e esquadrias de metal de pequeno e médio porte
}

\section{Environmental diagnosis of small and medium size manufacturing industries of metallic frames and metallic structures}

\author{
Patrícia Dal Moro' \\ Adalberto Pandolfo ${ }^{1}$ \\ Leila Dal Moro ${ }^{1}$ \\ Naira Elizabete Barbacovi ${ }^{1}$ \\ Leandro Doro Tagliari ${ }^{1}$
}

\begin{abstract}
Resumo: O crescimento populacional na última metade do século XX, acompanhado dos avanços tecnológicos, levou ao desenvolvimento acelerado das indústrias, o que ocasionou o aumento da poluição ambiental causada pelos resíduos sólidos. Assim, a legislação tem se tornado cada vez mais exigente, o que obriga as empresas a serem cada vez mais responsáveis, no que se refere à questão ambiental em sua estratégia operacional. Diante deste fato, este trabalho buscou realizar um diagnóstico ambiental em indústrias de fabricação de estruturas metálicas e esquadrias de metal de pequeno e médio porte, a fim de verificar as formas de fabricação, gerenciamento, resíduos sólidos gerados e os programas ambientais adotados. Para a obtenção das informações, foram visitadas 18 empresas, as quais participaram da aplicação de um questionário semiestruturado.
\end{abstract}

Palavras-chave: Resíduos sólidos. Indústrias metalúrgicas. Impactos ambientais.

\begin{abstract}
Population growth in the latter half of the $20^{\text {th }}$ century, accompanied by technological advances, led to the accelerated development of industries, which resulted in increased environmental pollution by solid waste. Legal aspects have increased considerably, demanding companies to be more responsible with regard to environmental issues in their operational strategy. Considering this fact, this study attempts to make an environmental diagnosis in small and medium-sized manufacturing industries of steel structures and frameworks in order to verify forms of manufacturing, management, solid waste generated, and environmental programs adopted. Information was collected in eighteen companies through semi-structured questionnaires.
\end{abstract}

Keywords: Solid waste. Metallurgical industries. Environmental impacts.

\section{Introdução}

A partir da revolução industrial, o desenvolvimento das indústrias ocorreu de forma acelerada e, desde então, a poluição ambiental causada pelo homem aumentou consideravelmente e de maneira descontrolada, o que leva as organizações a reformularem os setores de produção e gestão. Gerenciar o processo produtivo é de suma importância, pois melhorias simples geram grandes oportunidades, eficiência e ganhos.

Um mercado globalizado, competitivo, com legislação cada vez mais exigente e com uma preocupação em relação às questões ambientais e ao desenvolvimento sustentável está levando a sociedade a cobrar dos setores públicos e privados uma mudança na forma e desenvolvimento até então empregados e a adoção de programas ou sistemas de gerenciamento que atinjam e demonstrem um desempenho ambiental adequado, controlando os impactos das atividades industriais, produtos e serviços no meio ambiente (SERBER, 2009).

Quando se considera a participação de empresas de pequeno e médio porte isso é ainda mais relevante, particularmente em virtude de elas serem mais numerosas e produzirem uma maior diversidade de poluentes. Os padrões ambientais estabelecidos legalmente, muitas vezes, não contemplam as potencialidades dos danos ambientais associados à acumulatividade e ao sinergismo ou reatividade,

\footnotetext{
${ }^{1}$ Faculdade de Engenharia e Arquitetura - FEAR, Universidade de Passo Fundo - UPF, Campus I, CP 611, CEP 99001-970, Passo Fundo, RS, Brasil, e-mail: pati_dalmoro@hotmail.com; adalbertopandolfo@hotmail.com; leidalmoro@yahoo.com.br; nairabarbacovi28@gmail.com; leandrodorotagliari@gmail.com
} 
de compostos em um determinado espaço físico (SEIFFERT, 2011).

Algumas organizações que usam as estratégias ambientais como vantagem competitiva, com a implantação de normas e padronizações, obtêm ganhos resultantes da melhoria do processo, como a redução na geração de resíduos. No entanto, o principal fator, em caráter decisivo no processo de competitividade é representado pela imagem, tanto do produto quanto da organização, sendo ambos ambientalmente corretos. Em consequência disso, o que se estima é a redução de custos e aumento nos lucros a médio e longo prazo (DONAIRE, 1999).

\section{Referencial teórico}

\subsection{A indústria metalúrgica}

O Setor metalmecânico compreende uma grande variedade de atividades relacionadas à transformação dos metais, constituindo-se em um conjunto amplo e diversificado de setores, cuja característica principal consiste no fato de que o componente principal dos bens e serviços produzidos contempla tecnologias baseadas em conhecimentos e técnicas relacionados com a produção, processamento e utilização de metais, especialmente o ferro, o alumínio e o aço, entre outros tipos de ligas metálicas (FERREIRA, 2002).

A indústria metalúrgica é responsável pela fabricação de aço e de produtos siderúrgicos, produção de fundidos de ferro e aço, forjados, arames, relaminados com ou sem tratamento de superfície, inclusive galvanoplastia; metalurgia dos metais não ferrosos, em formas primárias e secundárias, inclusive ouro; produção de laminados, ligas, artefatos de metais não ferrosos com ou sem tratamento de superfície, inclusive galvanoplastia; relaminação de metais não ferrosos, inclusive ligas, produção de soldas e ânodos; metalurgia de metais preciosos; metalurgia do pó, inclusive peças moldadas; fabricação de estruturas metálicas com ou sem tratamento de superfície, inclusive; galvanoplastia, fabricação de artefatos de ferro, aço e de metais não ferrosos com ou sem tratamento de superfície, inclusive galvanoplastia, têmpera e cementação de aço, recozimento de arames e tratamento de superfície (BRASIL, 2012).

Diante disso, a Fundação Estadual de Proteção Ambiental Henrique Luiz Roessler - FEPAM realizou um relatório em 2003 (FUNDAÇÃO..., 2003), no qual foram identificados os setores couro, mecânico e metalúrgico como as atividades com maior potencial de geração de resíduos perigosos (Classe I). Os setores alimentar, metalúrgico e químico são os maiores geradores de resíduos sólidos industriais não perigosos (Classe II). Sendo as indústrias metalúrgicas as responsáveis pela geração de 10,9\% dos resíduos perigosos e 13,63\% dos resíduos não perigosos, o que indica que o setor é um grande gerador de resíduos.
Neste sentido, Seiffert (2011) afirma que o meio empresarial ainda considera problemas ambientais como secundários, porém o governo passou a publicar, a partir de 1980, uma série de regulamentações, restringindo a poluição industrial. Portanto, isso vem precipitando uma mudança progressiva no ambiente de negócios das organizações, acarretando mudanças na sua forma de produção.

Uma forma de gerenciar os problemas ambientais é a implantação de um sistema de gestão ambiental, o qual identifica e avalia os aspectos e impactos ambientais, implanta programas de monitoramento ambiental, programas de recuperação ambiental, auditorias ambientais, inspeções ambientais, programas de minimização de carga poluidora, programas de análise e gerenciamento de riscos, emergências ambientais e educação ambiental (SERBER, 2009).

$\mathrm{O}$ aumento dos impactos ambientais provocados pelos processos promoveu o surgimento da preocupação da sociedade com a qualidade ambiental. Isto, associado à rigorosa legislação ambiental, foi responsável pela busca por formas de racionalizar o uso de recursos naturais e minimizar a geração de resíduos no ramo industrial (ZBONTAR; GLAVIC, 2000). Por outro lado, a maioria das preocupações ambientais pode ser relacionada com aspectos econômicos, uma vez que a redução no consumo de materiais e de energia está diretamente ligada com benefícios financeiros, além das melhorias ambientais (MEINDERS; MEUFFELS, 2001).

Os impactos ambientais estão relacionados diretamente com o ramo de atividade e o porte das empresas. Em empresas de pequeno e médio porte, a intensidade do impacto causado por suas atividades requer um uso de tecnologias mais adequadas. $\mathrm{O}$ maior impacto ambiental da empresa torna-a mais susceptível de ser apontada como uma das causadoras de problemas ambientais e, consequentemente, sujeita a ações dos agentes preocupados com essa questão (SEIFFERT, 2011).

Segundo a Resolução CONAMA No 001/86 (BRASIL, 1986, p. 01), para a legislação brasileira, considera-se impacto ambiental:

[...] qualquer alteração das propriedades físicas, químicas e biológicas do meio ambiente, causada por qualquer forma de matéria ou energia resultante das atividades humanas que, direta ou indiretamente, afetam: I - a saúde, a segurança e o bem estar da população; II - as atividades sociais e econômicas; III - a biota; IV - as condições estéticas e sanitárias do meio ambiente; e V - a qualidade dos recursos ambientais.

Mayolo e Perini (2012) destacam que a busca por reduzir os impactos ambientais é voltada para ações de como tornar os métodos de produção mais eficazes a fim de reduzir a geração de resíduos sólidos e o 
consumo de matéria-prima, realizar o gerenciamento de resíduos sólidos gerados no processo produtivo, buscando segregar, acondicionar e dar destinação correta, além de controlar as emissões atmosféricas.

Existe uma carência de informações, por parte das empresas, sobre as inúmeras possibilidades de adequar o processo produtivo, como coleta seletiva, redução do consumo de matéria-prima e, com isso, obter ganhos financeiros (MANTOVANI; TAUCHEN, 2009).

\section{Metodologia}

O diagnóstico foi realizado em dezoito empresas de fabricação de estruturas metálicas e esquadrias de metal de pequeno e médio porte do município de Marau, RS. Para a obtenção dos dados, foi utilizado um questionário semiestruturado. A sequência lógica adotada para o desenvolvimento da pesquisa está dividida em fases, conforme fluxograma da Figura 1.

\subsection{Identificação do processo de gerenciamento}

Nesta fase inicial, foram coletados dados a fim de verificar a forma como é realizado o processo de gerenciamento das indústrias de fabricação de estruturas metálicas e esquadrias de metal. A identificação foi realizada em visitas às empresas de pequeno e médio porte, nas quais foram realizadas entrevistas junto à gerência e à área técnica das indústrias, com coleta de dados, tendo como objetivo, identificar os procedimentos que são adotados para o gerenciamento.

A seguir, apresenta-se a estrutura de necessidades e informações mínimas que foram identificadas referentes aos procedimentos de planejamento que são realizados pelas empresas.

- Existe um planejamento na produção da empresa?

- Qual o setor que realiza?

- Existe comunicação entre os setores de planejamento e produção?

- São gerados os documentos?

- Como são armazenados esses documentos?

\subsection{Identificação das formas de fabricação}

Para identificar as formas de fabricação de estruturas metálicas e esquadrias de metal, foram realizadas visitas às empresas em estudo e aplicado o questionário ao profissional responsável pela parte ambiental da empresa.

A seguir, apresenta-se a estrutura de necessidades e informações mínimas a serem identificadas referentes às formas de fabricação que são realizadas pelas empresas.

- A empresa tem um controle sobre o processo fabril?

- São gerados documentos?

- Quais documentos são gerados?

- Esses documentos informam defeitos ou falhas no processo?

\subsection{Identificação dos programas ambientais}

Nesta fase, foram realizadas visitas às indústrias de fabricação de estruturas metálicas e esquadrias de metal, para identificar se as indústrias haviam adquirido os programas ambientais adotados pelas empresas.

Etapa 1 - Diagnóstico da situação atual das indústrias de fabricação de estruturas metálicas e esquadrias de metal do município de Marau, RS.

$\downarrow$

Fase 1.1 - Identificação do processo de gerenciamento

\begin{tabular}{|c|}
\hline Fase 1.1 - Identificação do processo de gerenciamento \\
\hline Fase 1.2 - Identificação das formas de fabricação \\
\hline Fase 1.3 - Identificação dos programas ambientais \\
\hline Fase 1.4 - Identificação dos resíduos gerados no processo de fabricação \\
\hline \\
Fase 1.5 - Identificação dos aspectos e impactos gerados na fabricação \\
\hline
\end{tabular}

Figura 1. Estrutura metodológica para o desenvolvimento da pesquisa. Fonte: Elaborado pelos autores. 
A seguir, apresenta-se a estrutura de necessidades e informações a serem analisadas referentes ao sistema de gestão ambiental.

- A empresa adquiriu algum equipamento que reduza o consumo de energia nos últimos anos?

- A empresa adquiriu algum equipamento que reduza o consumo de matéria-prima nos últimos anos?

- A empresa adquiriu algum equipamento que reduza o consumo de água nos últimos anos?

- A empresa adquiriu algum equipamento para tratamento dos efluentes gerados no processo produtivo no último ano?

- A empresa possui licenciamento ambiental?

- A empresa possui programas ambientais?

- A empresa tem prevenção e preservação ambiental?

- A empresa tem um departamento ambiental?

- A empresa tem um profissional habilitado para cuidar da área ambiental?

- A empresa possui recursos específicos para questões ambientais?

- Quantas horas/ mês são gastas com questões ambientais?

- A empresa tem um sistema de gestão ambiental?

- A empresa tem conhecimento dos benefícios do sistema de gestão?

- A empresa sente falta de incentivo?

- A empresa tem uma política ambiental?

- A empresa busca cumprir os requisitos legais?

- A empresa têm objetivos e metas?

- As questões ambientais fazem parte da visão estratégica da empresa?

- A empresa realiza ou realizou no último ano treinamentos para funcionários sobre questões ambientais?

- Os clientes cobram a adoção de práticas ambientais?

- A sua empresa tem interesse em implantar um sistema de gestão ambiental?

\subsection{Identificação dos resíduos gerados no processo de fabricação}

Nesta fase, foram verificadas as formas de fabricação de esquadrias de metal e estruturas metálicas nas indústrias, para identificar os resíduos gerados no processo fabril. Para a obtenção destes dados, foram realizadas visitas e entrevistas aos profissionais responsáveis pela parte ambiental das empresas.

A seguir, apresenta-se a estrutura de necessidades e informações a serem analisadas com relação aos resíduos gerados no processo de fabricação.
- Quais resíduos são gerados?

- Há segregação dos resíduos?

- Há controle dos resíduos gerados?

- Quais as formas de controle?

- Quais são os responsáveis pelo controle dos resíduos gerados?

- Qual é o destino desses resíduos?

\subsection{Identificação dos aspectos e impactos gerados no processo de fabricação}

Para identificar os aspectos e impactos gerados no processo de fabricação de esquadrias de metal e estruturas metálicas das indústrias, foram analisadas as formas de gerenciamento e fabricação e os resíduos gerados no processo produtivo.

- Quais são os principais resíduos gerados?

- Qual é a destinação dos resíduos sólidos?

- A empresa gera efluente no processo produtivo?

- A empresa possui caldeira ou fornalha?

- A empresa verifica a presença de material particulado?

- A empresa realiza algum controle dessa emissão?

- A empresa realiza pintura?

- A empresa possui cabine de pintura?

- A empresa possui jato de granalha?

- A empresa possui cabine de jateamento?

\section{Resultados}

\subsection{Identificação do processo de gerenciamento}

Nesta etapa, verificou-se que as empresas de pequeno porte são empresas familiares e o número de funcionários não ultrapassa dez. Dessa maneira, quem gerencia e realiza as formas de fabricação são os proprietários. Para Cragg, Caldeira e Ward (2011), os proprietários e funcionários de pequenas e médias empresas desenvolvem múltiplas funções para lidar com a indisponibilidade de recursos. Do total de empresas de pequeno porte consultadas, $5,55 \%$ afirmaram que não realizam nenhuma forma de planejamento e controle; $5,55 \%$ informaram que prestam serviço exclusivo para outra indústria metalúrgica de grande porte, demonstrando que quem realiza o planejamento é a empresa contratante. Além disso, $11,11 \%$ das empresas possuem um setor de planejamento, custo e produção o qual é responsável pelas questões ambientais.

Em relação à comunicação entre os setores, $100 \%$ das empresas afirmaram ter uma comunicação sobre o processo de fabricação. Destas, 38,88\% geram documentos informando o gerenciamento do processo de fabricação. Esse controle é armazenado em arquivos de papel e em meio digital, sendo que os arquivos de 
papel ficam guardados por um período determinado pela empresa, e depois são descartados.

\subsection{Identificação das formas de controle de fabricação}

As formas de controle de fabricação das empresas se dão por meio da demanda de serviços realizados diretamente pelos clientes. Com isso, $72,22 \%$ das empresas têm controle da produção e armazenam seus dados em documentos gerados, na maioria das empresas, em papel, e que ficam armazenados por um período determinado pela direção da empresa. Dessas empresas que controlam a produção, 27,78\% informam em seus registros defeitos ou falhas no seu processo produtivo, por meio do registro de não conformidade (RNC).

Considera-se planejamento e controle da produção como um processo que visa garantir que o planejamento estratégico da empresa seja atendido em acordo com as decisões adequadas para manter o desenvolvimento e competitividade da organização, assim garantir uma produção eficaz e com capacidade produtiva (AHUJA; KHAMBA, 2008).

\subsection{Identificação dos programas ambientais}

Nessa etapa, identificaram-se os programas ambientais adotados pelas empresas em estudo. $\mathrm{Na}$ identificação destes programas, verificou-se que existem ações relacionadas à aquisição de equipamentos que reduzem o consumo de energia elétrica, água e matéria-prima nas empresas (Figura 2).

Pode-se observar que $22,22 \%$ das empresas adquiriram equipamentos para reduzir o consumo de energia elétrica. Dessas, 5,55\% adequaram apenas a cobertura do pavilhão deixando entrar mais luz natural. Em 16,67\% das empresas, foram implantadas cisternas que captam a água da chuva. Uma das empresas salientou que conseguiu reduzir em 50\% o consumo de água após a implantação. Mantovani e Tauchen (2009) identificam que a captação de água pluvial é a mais aconselhável nos setores metalmecânico por apresentarem grande área de cobertura. A aquisição de equipamentos para reduzir o consumo de matéria-prima foi identificada em $11,11 \%$ das empresas.

Mayolo e Perini (2012) destacam que existe uma deficiência na efetivação de melhorias ambientais devido ao alto custo associado a investimentos e aquisições que buscam ações de redução do consumo de energia elétrica, reaproveitamento da água e melhorias no processo. Algumas empresas possuem o hábito de contabilizar os valores investidos nas ações ambientais, porém não mensuram seus investimentos para verificar se obtiveram redução de algum custo.
Nenhuma das empresas estudadas gera efluente industrial no seu processo fabril. Das empresas, $11,11 \%$ utilizam água no setor de corte, porém a água utilizada é apenas para minimizar os materiais particulados provenientes do corte. A água evapora com o tempo e, após a evaporação, o resíduo do corte é recolhido e encaminhado para empresas terceirizadas, licenciadas para a destinação correta.

Os programas ambientais adotados pelas empresas estudadas são apresentados na Figura 3.

Verificou-se que a coleta seletiva é adotada por $88,89 \%$ das empresas, sendo que é um requisito para o licenciamento ambiental. Sendo 11,11\% das empresas de pequeno porte e sem licenciamento ambiental, não realizam a coleta seletiva, enquanto que $5,56 \%$ das empresas estão em fase de implantação da política ambiental e do calendário ecológico. Em 16,67\% das empresas, foi realizada educação ambiental aos funcionários, abordando apenas as questões relativas aos resíduos sólidos. A gestão de resíduos é adotada por $33,33 \%$ das empresas.

Mayolo e Perini (2012) destacam que, das principais ações realizadas no que concerne ao gerenciamento ambiental, são consideradas mais efetivas as que objetivam tratar os efluentes industriais, controlar o consumo de matéria-prima, reduzir o consumo de

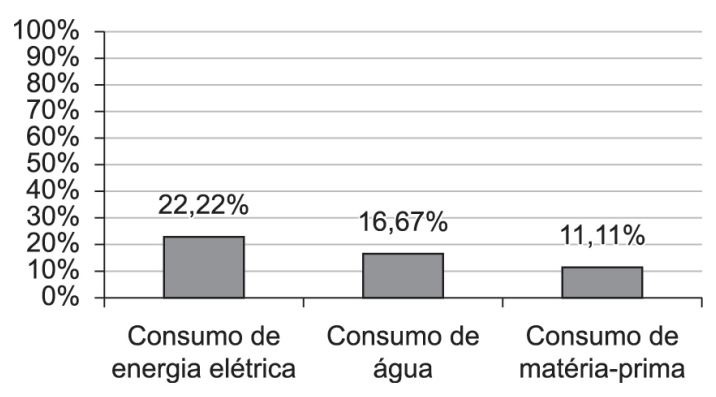

Figura 2. Aquisição de equipamentos para redução de consumo de água, energia elétrica e matéria-prima. Fonte: Elaborado pelos autores.

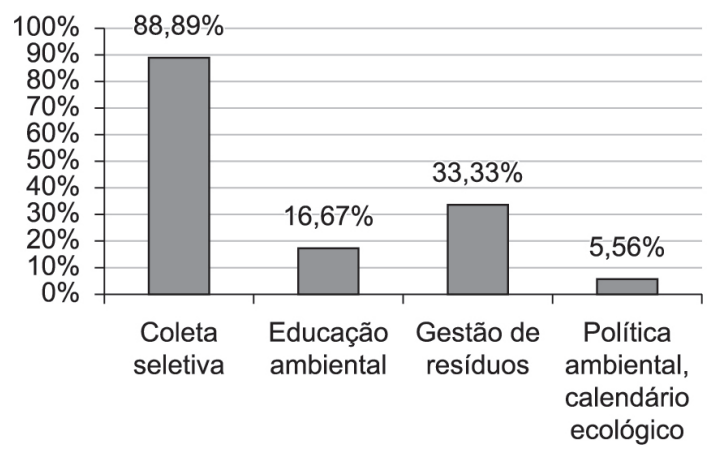

Figura 3. Programas ambientais adotados pelas empresas. Fonte: Elaborado pelos autores. 
energia elétrica, reduzir e dar destinação final aos resíduos sólidos.

A prevenção ambiental é observada em 16,66\% das empresas, as quais informaram que a única prevenção utilizada é a educação ambiental, mas $100 \%$ delas informaram que sabem da importância em adotar medidas preventivas em suas empresas. Para Ricardo (2009), a prevenção ambiental é uma das preocupações do meio empresarial, que visa priorizar a prevenção à poluição e eliminar os resíduos/ efluentes. Dessa forma, torna-se possível minimizar, controlar e modificar o processo produtivo.

Nenhuma das empresas tem um setor específico para tratar das questões ambientais. Verificou-se que as empresas de pequeno porte com no máximo dez funcionários não veem a necessidade de contratar um profissional habilitado para tratar das questões ambientais da empresa, porém todos salientam a importância de se ter um setor ou, então, que sejam contratadas empresas terceirizadas para prestar esses serviços.

Em relação aos profissionais da área ambiental que atuam nas empresas, 5,56\% possuem uma pessoa com formação em gestão ambiental e 5,56\% destas tem a contratação de uma empresa terceirizada. Pode-se perceber que nos dois casos são as empresas com maior número de funcionários. Para Mayolo e Perini (2012), em geral não há um cargo específico para atuar no exercício da função, as atividades de proteção ambiental são atribuídas a profissionais de diferentes setores.

Verificou-se que nenhuma empresa tem um orçamento específico para questões ambientais. Possuem apenas recursos com disposição final de resíduos e o pagamento de serviços prestados por empresas terceirizadas. Mantovani e Tauchen (2009) informam que, em $31 \%$ das empresas, os recursos financeiros correspondem ao principal fator dificultador para as questões ambientais. Muitas empresas salientam que investimentos financeiros são o pior obstáculo que se coloca entre a industrialização e o meio ambiente.

A Figura 4 mostra a quantidade de horas destinadas por mês para o atendimento de questões ambientais.

Na Figura 4, visualiza-se que $38,89 \%$ das empresas não possuem um período determinado para cuidar das questões ambientais. Das empresas de médio porte, $16,67 \%$ destinam oito horas mensais para cuidar das questões ambientais, voltadas à destinação de resíduos sólidos, segregação e palestras; $16,67 \%$ destinam cinco horas mensais e $27,78 \%$ das empresas gastam duas horas mensais, sendo elas referentes à destinação de resíduos sólidos.

Quando perguntados sobre o sistema de gestão ambiental, muitas empresas não tinham conhecimento sobre o sistema. Tal conhecimento e seus benefícios são verificados em $11,11 \%$ das empresas, porém todas

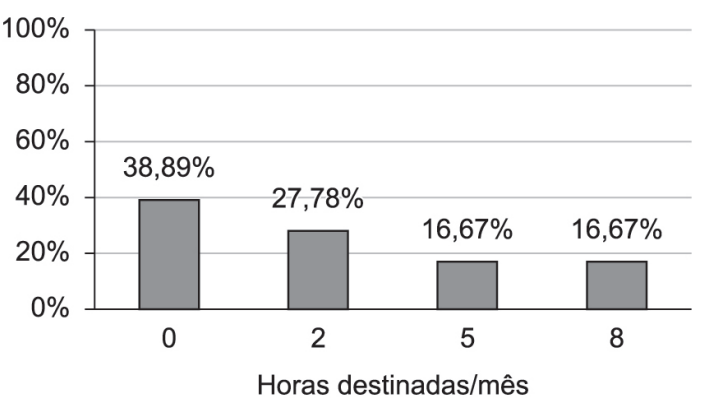

Figura 4. Horas destinadas às questões ambientais. Fonte: Elaborado pelos autores.

elas apontam a falta de auxílio e informação sobre como adequar o seu processo fabril, além do bônus com a implantação de políticas ambientais dos órgãos municipais, como redução de taxas ou impostos. Para Serber (2009), o sistema de gestão ambiental é uma condição indispensável nos últimos anos para obter redução de custos no processo, racionalização do uso de matéria-prima, redução de resíduos sólidos industriais, redução dos impactos ambientais, além de demonstrar seriedade e preocupação com as questões ambientais.

A política ambiental está em fase de elaboração em 5,56\% das empresas e 27,77\% delas informou não ter conhecimento. Mantovani e Tauchen (2009) informam que a intenção da política ambiental é definir o compromisso da organização com a melhoria contínua e o desempenho ambiental. A política ambiental deve estabelecer um senso geral de orientação para as organizações e simultaneamente fixar os princípios de ação pertinentes aos assuntos e à postura empresarial relacionados ao meio ambiente, deve ser descrita como forma de promover a mudança de comportamentos para alcançar a melhoria contínua (SANTOS et al., 2006).

Os requisitos legais estão sempre sofrendo alterações, assim as empresas necessitam criar meios para ter acesso a estas mudanças e incorporá-las em suas atividades (ZAMBRANO, 2005). Diante disso, $100 \%$ das empresas informaram que buscam cumprir, porém todas observam a falta de algum cumprimento.

A realização de treinamentos ocorre em $27,77 \%$ das empresas por meio de palestras aos funcionários a respeito de coleta seletiva, informando a classificação e a forma de armazenagem. Mantovani e Tauchen (2009) salientam os tipos de treinamento a ser ministrados a todos os colaboradores da empresa como conscientização sobre a importância estratégica da gestão ambiental, sobre as questões ambientais em geral, no aperfeiçoamento de habilidades e no cumprimento dos requisitos.

Nenhuma empresa tem objetivos e metas específicas para as questões ambientais. Porém, todas sabem que 
seria importante ter esse sistema na empresa. Uma vez estabelecidos os objetivos e metas, é realizado um planejamento buscando priorizar os impactos ambientais, e estabelecer programas para atingir os objetivos que visam reduzir os impactos e melhorar o desempenho ambiental (ZAMBRANO, 2005). As questões ambientais não fazem parte da visão estratégica de $11,11 \%$ das empresas.

Quando questionados sobre a adoção de práticas ambientais, 22,22\% das empresas, sendo elas de pequeno porte, e 5,56\% das empresas de médio porte informaram que os clientes não cobram a adoção de práticas ambientais.

A Figura 5 mostra o interesse das empresas em implantar um sistema de gestão ambiental no seu processo produtivo.

Nesta etapa, verificou-se que $33,33 \%$ das empresas, sendo todas elas de médio porte, têm interesse em buscar melhorias no seu processo produtivo com a implantação de um sistema de gestão ambiental. A partir da implantação, é possível assumir postura proativa em relação às questões ambientais incorporando práticas gerenciais. Além disso, trata-se de uma estratégia para que o empresário

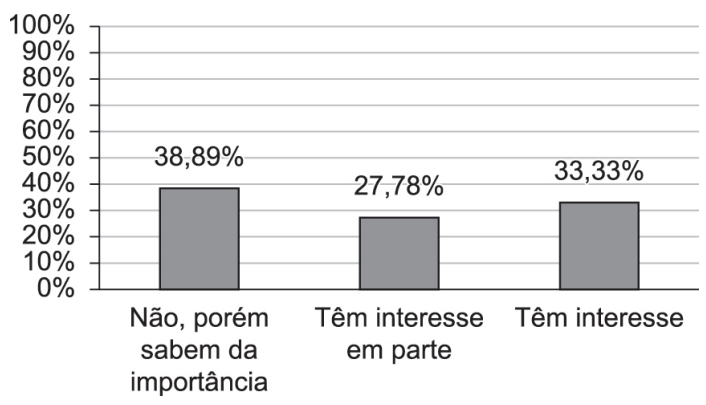

Figura 5. Implantação de um sistema de gestão ambiental. Fonte: Elaborado pelos autores. busque melhoria contínua no processo, identificando oportunidades de melhorias que reduzam os impactos das atividades da empresa sobre o meio ambiente, melhorando, simultaneamente, sua situação no mercado e suas possibilidades de sucesso (GHENO, 2006; LA ROVERE et al., 2002).

\subsection{Identificação dos resíduos gerados no processo de fabricação}

Nesta etapa, são apresentados os resultados obtidos referentes aos resíduos sólidos gerados no processo de fabricação. A Figura 6 apresenta os principais resíduos gerados no processo fabril das empresas.

Foi possível identificar que $100 \%$ das empresas geram resíduos como limalha de ferro, pó de ferro, retalho de ferro e varredura. Segundo Barbacovi (2013), os principais resíduos gerados nas indústrias de esquadrias metálicas em empresas de pequeno e médio porte são sucatas de metais, pó de ferro e resíduo de varrição. Destas, verificou-se que $88,89 \%$ realizam segregação dos resíduos e $72,22 \%$ têm controle sobre os resíduos gerados. O controle é realizado por meio dos recibos fornecidos pelas empresas terceirizadas responsáveis pela destinação final dos resíduos.

A falta de informação, sobre a destinação final dos resíduos sólidos é observada em 5,56\% das empresas. Tal fato ocasiona a contaminação dos resíduos sólidos pela falta de segregação. Depois da contaminação, a empresa tem um custo adicional para destinar os resíduos a empresas terceirizadas para posterior destinação final. Do contrário, se segregados os resíduos, a empresa pode obter ganhos e aumentar a receita. A logística reversa ocorre em $22,22 \%$ das empresas, porém apenas as latas de tintas e as lâmpadas fluorescentes são devolvidas para os fabricantes.

A reutilização de resíduos provenientes do processo fabril ocorre em 16,67\% das empresas de médio porte,

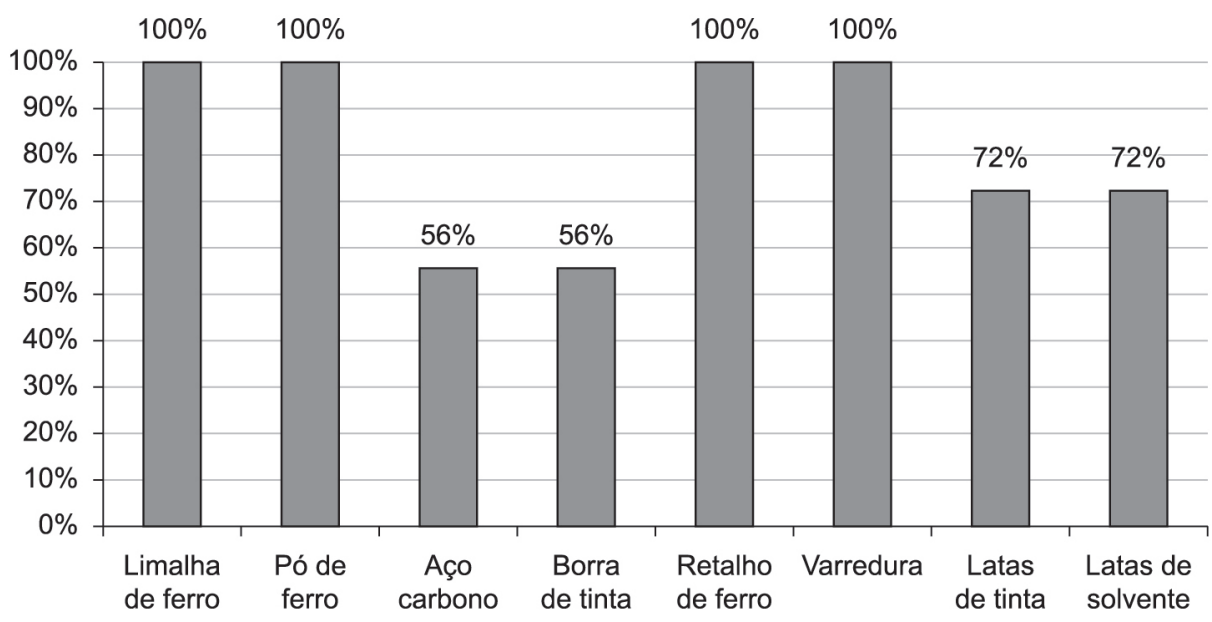

Figura 6. Resíduos gerados nas empresas estudadas. Fonte: Elaborado pelos autores. 
as quais reutilizam solventes e 5,56\% das empresas reutilizam limalha de ferro na fabricação de peso de portões que eles mesmos fabricam.

\subsection{Identificação dos aspectos e impactos gerados no processo de fabricação}

Identificou-se como principal impacto ambiental negativo a geração de resíduos sólidos nas indústrias de fabricação de estruturas metálicas e esquadrias de metal, abordados na etapa anterior.

A poluição das águas não é significativa, pois as empresas utilizam água na higienização de salas e escritórios, além da utilização nos sanitários; $11,11 \%$ das empresas utilizam água no seu processo produtivo no setor de corte, porém a quantidade de água utilizada é insignificante e não geram efluentes líquidos industriais.

Com relação à geração de efluentes sanitários, $44,44 \%$ das empresas possuem fossa séptica com posterior lançamento na rede pública; $33,33 \%$ das empresas, por utilizarem estruturas antigas, não sabem qual é o destino; e 22,22\% das empresas não realizam nenhum tipo de tratamento, destinando os seus efluentes para sumidouro (poço negro). Já para Mantovani e Tauchen (2009), 56\% das indústrias do setor metalmecânico utilizam o sistema de sumidouro (poço negro), o que é considerado irregular. Outros $16 \%$ ligam diretamente na rede pluvial e $6 \%$ apresentam condições favoráveis no destino dos efluentes sanitários

Em relação à poluição atmosférica, 5,56\% das empresas possuem fornalha, a qual é utilizada para diminuir a umidade do ar no processo de pintura; a presença de material particulado no seu processo fabril é observada em 100\% das empresas, principalmente no setor de corte, porém nenhuma empresa tem controle dessa emissão, embora forneça aos seus funcionários equipamento de segurança individual (EPIs).

O processo de jateamento ocorre em $16,67 \%$ das empresas, sendo que, em $11,11 \%$, adaptaram o seu processo com a implantação de uma cabine de jateamento adaptada à situação da empresa.

O jato de granalha é um processo mecânico no qual a superfície metálica é submetida ao impacto de um jato de microesferas de aço a alta velocidade. Este processo é utilizado para limpar o material metálico e eliminar possíveis corrosões superficiais. (TAGLIARI, 2012).

O processo de pintura é realizado em $50 \%$ das empresas. Destas, $27,78 \%$ possuem cabine de pintura adaptada à situação de cada empresa e 22,22\% delas não têm nenhuma forma de controle, realizando pintura até mesmo a céu aberto.

\section{Considerações finais}

O presente trabalho partiu do pressuposto de que a questão ambiental nas indústrias de fabricação de estruturas metálicas e esquadrias de metal de pequeno e médio porte possuem alguma deficiência. Observaram-se as dificuldades enfrentadas, porém nenhuma das empresas possui um sistema de gestão ambiental e muitas delas não têm conhecimento sobre o sistema.

Depois das visitas realizadas às empresas, verificou-se que a maioria delas não possui um sistema de gerenciamento e planejamento da produção e, portanto, não possui controle de matéria-prima utilizada e quantidade de resíduos sólidos gerados.

As questões ambientais nas indústrias estudadas buscam primeiramente atender às medidas impostas pelo licenciamento ambiental, as quais são exigidas pelos órgãos regulamentadores. Identificou-se que existe preocupação apenas no final do processo e que as ações empregadas são originadas pela necessidade de melhoria de processo fabril, buscando a inter-relação entre eficiência produtiva e redução na utilização de recursos. A maioria das empresas não investe em ações que ajudem a minimizar ou eliminar geração de resíduos, como foi apresentado na análise dos dados. Mantovani e Tauchen (2009) destacam que as novas tecnologias permanecem na mão de grandes corporações, não chegando à mão de pequenas empresas.

As empresas de pequeno porte do ramo familiar são as que mais apresentam deficiência, tanto de informações como de investimentos com as questões ambientais. Com isso, vê-se a necessidade de incentivo dos órgãos regulamentadores, buscando suprir a deficiência das empresas, levando informações de como melhorar o seu processo produtivo e de como atender aos requisitos legais. Os incentivos para a redução da poluição podem ser econômicos, como verbas monetárias, empréstimos, ou taxa de crédito entregues às empresas para que possam desempenhar estratégias de minimização dos impactos (BOLLINO; MICHELI, 2012).

Identificou-se a importância em realizar análises identificando os aspectos e impactos ambientais envolvidos no processo produtivo e a necessidade de implantação de um sistema de gestão ambiental para as indústrias de pequeno e médio porte, buscando o comprometimento de todos os setores da organização para, com isso, buscar um gerenciamento dos processos com a aplicação do ciclo do PDCA, visando à eficiência dos recursos naturais, diminuição da geração de resíduos e, consequentemente, a diminuição de despesas.

\section{Referências}

AHUJA, I. P. S.; KHAMBA, J. S. Justification of total productive maintenance initiatives in Indian manufacturing industry for achieving core competitiveness. Journal of Manufacturing Technology Management, v. 19, n. 5, p. 645-669, 2008. http:// dx.doi.org/10.1108/17410380810877302 
BARBACOVI, N. E. Gerenciamento de resíduos industriais: uma avaliação de desempenho ambiental aplicado nas indústrias metal-mecânica em um município de médio porte. 2013. 122 f. Dissertação (Mestrado em Engenharia Civil e Ambiental)-Universidade de Passo Fundo - UPF, Passo Fundo, 2013.

BOLLINO, C. A.; MICHELI, S. On the relative optimality of environmental policy instruments: an application of the work of Alberto Alesina. Atlantic Economic Journal, v. 40, n. 4, p. 385-399, 2012. http://dx.doi. org/10.1007/s11293-012-9338-y

BRASIL. Ministério da Previdência Social. Classificação Nacional de Atividade Econômica - CNAE 2.0. Anexo I. Classificação nacional de atividades econômicas e grau de risco de acidente do trabalho associado. 2012. Disponível em: <http://www.mpas.gov.br/arquivos/ office/4_101130-164603-107.pdf >. Acesso em: 10 nov. 2012.

BRASIL. Ministério do Meio Ambiente. Conselho Nacional do Meio Ambiente - CONAMA. Resolução CONAMA $\mathrm{n}^{\circ} 1$, de 23 de janeiro de 1986. Dispõe sobre critérios básicos e diretrizes gerais para a avaliação de impacto ambiental. Diário Oficial da República Federativa do Brasil, Brasília, DF, 17 fev. 1986. Seção 1, p. 2548-2549.

CRAGG, P.; CALDEIRA, M.; WARD, J. Organizational information systems competences in small and mediumsized enterprises. Information \& Management, v. 48, n. 8, p. 353-363, 2011. http://dx.doi.org/10.1016/j. im.2011.08.003

DONAIRE, D. Gestão ambiental na empresa. 2. ed. São Paulo: Atlas, 1999.

FERREIRA, M. S. A formação de redes de conhecimento nas indústrias metal-mecânica de confecções de Nova Friburgo. 2002. 147 f. Tese (Mestrado em Engenharia da Produção)-COPPE, Universidade Federal do Rio de Janeiro - UFRJ, Rio de Janeiro, 2002.

FUNDAÇÃO ESTADUAL DE PROTEÇÃO AMBIENTAL HENRIQUE LUIS ROESSLER - FEPAM. Relatório sobre a geração de resíduos sólidos industriais do Estado do Rio Grande do Sul. Porto Alegre: FEPAM, 2003. Disponível em: <http://www.fepam. rs.gov.br/biblioteca/rsi.asp>. Acesso em: 12 out. 2012.

GHENO, R. Sistema de gestão ambiental e benefícios para a organização: estudo de caso em empresas metalúrgicas do RS. 2006. 149 f. Dissertação (Mestrado em Engenharia: Infraestrutura e Meio Ambiente)Universidade de Passo Fundo - UPF, Passo Fundo, 2006. PMid:16783990.

LA ROVERE, E. L. et al. Manual de auditoria ambiental de Estações de Tratamento de Esgotos. Rio de Janeiro: Qualitymark, 2002.
MANTOVANI, C. A.; TAUCHEN, J. A. Um Modelo de Gestão do Desenvolvimento para o setor industrial metal-mecânico da região Fronteira Noroeste do Rio Grande do Sul, através da Gestão Ambiental. Horizontina: Fundação de Amparo à Pesquisa do Estado do Rio Grande do Sul - FAPERGS, 2009. 75 p. (Relatório Técnico PROCOREDES, IV).

MAYOLO, L. L. K.; PERINI, R. L. Diagnóstico do perfil de Gestão Ambiental das empresas de médio porte do setor metalmecânico de Caxias do Sul. Global Manager Acadêmica, v. 1, n. 2, p. 1-20, 2012.

MEINDERS, H.; MEUFFELS, M. Product chain responsibility - an industry perspective. Corporate Environmental Strategy, v. 8, n. 4, p. 348-354, 2001. http://dx.doi.org/10.1016/S1066-7938(01)00111-7

RICARDO, R. Análise dos benefícios ambientais resultante da implantação do sistema de gestão ambiental em conformidade com a Norma ISO 14.001:2004 em uma indústria metalúrgica na cidade de São Joaquim da Barra - SP. 2009. 79 f. Dissertação (Mestrado em Tecnologia Ambiental)-Universidade de Ribeirão Preto - UNAERP, Ribeirão Preto, 2009.

SANTOS, R. et al. Stakeholder participation in the design of environmental policy mixes. Ecological Economics, v. 60, n. 1, p. 100-110, 2006. http://dx.doi.org/10.1016/j. ecolecon.2005.11.025

SEIFFERT, M. E. B. ISO 14001 sistemas de gestão ambiental: implantação objetiva e econômica. 4. ed. São Paulo: Atlas, 2011.

SERBER, S. L. Proposta de implantação e certificação de um sistema de gestão ambiental: estudo de caso de indústria metal-mecânica. 2009. 181 f. Dissertação (Mestrado em Engenharia Ambiental)-Universidade do Estado do Rio de Janeiro - UERJ, Rio de Janeiro, 2009.

TAGLIARI, L. D. Planejamento do processo de produção mais limpa em uma empresa metalmecânica. 2012. 180 f. Dissertação (Mestrado em Engenharia)-Universidade de Passo Fundo - UPF, Passo Fundo, 2012.

ZAMBRANO, T. F. Sistemática para auxiliar as pequenas empresas industriais da cidade de São Carlos na identificação e análise dos impactos ambientai gerados durante o processo produtivo. 2005. 147 f. Dissertação (Mestrado em Engenharia de Produção)-Universidade Federal de São Carlos - UFSCAR, São Carlos, 2005.

ZBONTAR, L.; GLAVIC, P. Total site: wastewater minimization: wastewater reuse and regeneration reuse. Resources, Conservation and Recycling, v. 30, n. 4, p. 261-275, 2000. http://dx.doi.org/10.1016/ S0921-3449(00)00064-1 